\title{
lodine knowledge is positively associated with dietary iodine intake among women of childbearing age in the UK and Ireland
}

\author{
S. Maria O'Kane, L. Kirsty Pourshahidi, Kayla M. Farren, Maria S. Mulhern, J. J. Strain and Alison J. Yeates* \\ School of Biomedical Sciences, Northern Ireland Centre for Food and Health (NICHE), Ulster University, Cromore Road, \\ Coleraine, County Londonderry, BT52 1SA, UK
}

(Submitted 19 May 2016 - Final revision received 12 October 2016 - Accepted 14 October 2016 - First published online 18 November 2016)

\begin{abstract}
Adequate I intake is important before conception and during pregnancy for optimal infant neurodevelopment. Recent studies have highlighted the prevalence of I deficiency in the UK and Ireland. It is possible that optimal I intake may be impeded by a poor knowledge of I nutrition. This study aimed to investigate I knowledge among women of childbearing age in the UK and Ireland and to determine whether a relationship exists between I knowledge and dietary I intake. Females (aged 18-45 years) were invited to complete an online questionnaire, which assessed knowledge of I and estimated dietary I intake using a FFQ. A total of 520 females of childbearing age completed the study. I knowledge was poor; only one-third (32\%) of the participants correctly identified pregnancy as the most important stage of the lifecycle for I, and $41 \%$ of participants could not correctly identify any health problem related to I deficiency. The median daily I intake was estimated as $152 \mu \mathrm{g} / \mathrm{d}$. Almost half ( $46 \%$ ) of the participants failed to meet dietary recommendations $(140 \mu \mathrm{g} / \mathrm{d}$ ) for I. A higher dietary I intake was positively associated with greater I knowledge $(r 0.107 ; P=0.016)$. This study suggests that knowledge of I nutrition is low among women of childbearing age, and those with a greater knowledge of I nutrition had a higher dietary I intake. Initiatives to educate women of childbearing age on the importance of I nutrition should be considered as part of a larger public health strategy to address I deficiency.
\end{abstract}

Key words: Iodine: Iodine knowledge: Women of childbearing age: Dietary iodine intake

I is a trace element necessary for the synthesis of thyroid hormones, triiodothyronine and thyroxine, which are critical for human growth and development ${ }^{(1,2)}$. I is particularly important during pregnancy for brain and neurological development ${ }^{(3)}$. Severe I deficiency during pregnancy can cause cretinism, a condition of mental and physical impairment ${ }^{(1)}$. Even mildto-moderate I deficiency during pregnancy can impair cognitive development in the offspring ${ }^{(4)}$. Of particular public health concern in the UK and Ireland is the prevalence of mildto-moderate I deficiency in women of childbearing age ${ }^{(5-7)}$

Adequate dietary I intake is required before conception and during pregnancy to meet the requirement for increased maternal thyroid hormone synthesis, I renal clearance and I transfer to the fetus ${ }^{(8,9)}$. Much debate surrounds the UK dietary recommendations for I, which have not been updated in more than 20 years, and, despite the WHO recommending an incremental intake of $250 \mu \mathrm{g} / \mathrm{d}$ during pregnancy, in the UK, the dietary recommendation for both pregnant women and women of childbearing age remains at $140 \mu \mathrm{g} / \mathrm{d}^{(10,11)}$.

There are a number of dietary factors that may increase the risk of I deficiency in women of childbearing age: consumption of seafood and dairy products is lower compared with other population groups; milk consumption is declining; and there is limited consumption of I-containing supplements ${ }^{(12-14)}$. Organic milk is increasing in popularity and as it typically contains $30 \%$ less I than conventional cow's milk, and those who replace conventional cow's milk with organic milk are likely to have a reduced I intake ${ }^{(15)}$. The most recent National Diet and Nutrition Survey reported that women aged 19-64 years have a median I intake of 130 (interquartile range 48-283) $\mu \mathrm{g} / \mathrm{d}$ and $10 \%$ have a daily I intake below the lower reference nutrient intake $(\mathrm{LRNI})^{(12)}$. In the UK and Ireland, there is currently no national strategy to address I deficiency. Along with other European countries, an iodised salt programme as recommended by the WHO in order to increase I intake and to eliminate I deficiency has not been implemented $^{(11)}$. As a consequence, the availability of iodised salt in the UK is low and is unlikely to contribute significantly to I intake ${ }^{(16)}$.

It has been suggested that a low level of knowledge surrounding $I$ is a major factor contributing to the risk of I deficiency ${ }^{(17-22)}$. Studies of pregnant women in Australia reported that more than half of the participants could not identify any adverse health problem related to I deficiency, and only $19 \%$ were aware that they needed I supplements ${ }^{(23,24)}$. Furthermore, a recent UK study reported that the majority of

Abbreviations: LRNI, lower reference nutrient intake; RNI, reference nutrient intake; UIC, urinary iodine concentration.

* Corresponding author: Dr A. Yeates, fax +44 287012 4965, email a.yeates@ulster.ac.uk 
pregnant women were aware of the general diet and lifestyle recommendations during pregnancy but knowledge of I nutrition was low ${ }^{(22)}$. Improving public knowledge and awareness of I nutrition may play an important role in reducing the prevalence of I deficiency.

To our knowledge, there are no public education initiatives aimed at improving I knowledge in the UK or Ireland. Although the level of I knowledge in pregnant women and mothers of children aged 0-36 months has been previously reported ${ }^{(22)}$, I knowledge in women of childbearing age is currently unknown. Women of childbearing age, pregnant women and those planning a pregnancy in the UK are not routinely provided with specific dietary I information, and the availability of scientifically accurate I nutrition information is limited to one fact sheet produced by the British Dietetic Association ${ }^{(9,25)}$.

The present study, therefore, aimed to investigate I knowledge and awareness among women of childbearing age in the UK and Ireland, and to determine whether a relationship exists between I knowledge and dietary I intake.

\section{Methods}

The present study was conducted according to the guidelines laid down in the Declaration of Helsinki, and all procedures involving human subjects were approved by Ulster University, School of Biomedical Sciences, Ethics Filter Committee. Data were collected anonymously, and participants were advised that by completing the questionnaire they were giving consent for their data to be used for the present study. On the basis of an estimated $10 \%$ of women failing to meet the LRNI ${ }^{(12)}(\alpha=0 \cdot 10$, $\beta=0.8)$, the sample size calculation estimated a requirement of a minimum of $n 448$ subjects.

Females of childbearing age (18-45 years) were invited to complete a twenty-nine-item questionnaire (online Supplementary Material), which was administered online using SurveyMonkey $^{\circledR}$ from 23 February to 16 March 2015. The questionnaire was designed to assess I nutrition knowledge and dietary I intake. Participants were also asked to provide general demographic information on age, ethnicity, education and employment status. Information was also collected on the diagnosis of a thyroid condition, smoking status, pregnancy and lactation. The questionnaire was pre-tested and modified to ensure there was no ambiguity in the questions and to identify any potential problems the user might experience when completing the survey.

The study was advertised via emails to Ulster University staff and students and externally through social media.

\section{Assessment of iodine knowledge}

Questions to assess I knowledge were adapted from previous I knowledge studies ${ }^{(17,21,23,26)}$. Participants were asked five questions in this section on their knowledge and awareness of (a) the nutrient I (see question 11 in the online Supplementary Material), (b) the food sources of I (question 12), (c) health problem(s) associated with I deficiency (question 13), (d) the most at-risk population group(s) (question 14) and (e) I deficiency as a current health concern in the UK and Ireland (question 15). The questionnaire also asked whether participants had ever received information on $\mathrm{I}$ and collected information on these resources.

On the basis of the Jooste et al. ${ }^{(17)}$ questionnaire, scores for the four individual questions assessing I knowledge (see questions 12-15 above) were combined to calculate a total I knowledge score ranging from 0 to 8 . The maximum scores available for each question were as follows: question 12 (1), question 14 (1) and question 15 (1). There was a total of five correct answers for question 13, and for each correct answer (goitre, mental retardation, malformations in pregnancy (birth defects), impaired physical development during childhood and blindness) selected, participants were awarded 1 point (for a total of five). Total I knowledge scores were categorised into four levels as follows: (a) score 0, (b) score 1-3, (c) score 4-6 and (d) score $7-8$, with a score of 0 indicating poor I knowledge and 7-8 indicating excellent I knowledge. For multiple-choice questions, random order of answers was utilised.

\section{Assessment of iodine intake}

The questionnaire incorporated the previously validated Glasgow Iodine FFQ to estimate intake of I-containing foods over the previous 6 months ${ }^{(27)}$. The Glasgow Iodine FFQ was modified to include intake of eggs owing to evidence that eggs can contribute to the total dietary I intake ${ }^{(14)}$. Food sources of I were grouped into nine categories: milk, eggs, oily fish, white fish, other seafood, yogurts, cheese, cheese-based dishes, and milk- or cream-based puddings. Participants were asked to record how frequently they consumed each food group (per day, per week or per month). The I content of all foods included in the questionnaire was sourced from the UK food composition database, and information on typical portion size was obtained ${ }^{(28)}$. These data were then combined to estimate the total daily I intake $(\mu \mathrm{g} / \mathrm{d})$ and the intake from the following food groups: milk, eggs, fish and other dairy products. Participants were also asked about their use of I containing supplements (i.e. frequency of consumption, dose, brand, duration).

\section{Statistical analysis}

Statistical analyses were conducted using Statistical Package for Social Sciences, version 22. Descriptive statistics were conducted for all outcome variables. Participants were categorised into five age groups: (a) 18-25 years, (b) 26-30 years, (c) 31-35 years, (d) 36-40 years and (e) 41-45 years. Participants were also categorised according to I intake: (a) below the LRNI $(70 \mu \mathrm{g} / \mathrm{d})$, (b) between the LRNI and the reference nutrient intake (RNI) $(70 \cdot 1-139.9 \mu \mathrm{g} / \mathrm{d}$ ) and (c) meeting the RNI $(\geq 140 \mu \mathrm{g} / \mathrm{d})^{(10)}$. Normality was assessed using the KolmogorovSmirnov test. To investigate the effect of demographic characteristics on total I knowledge scores, $\chi^{2}$, Mann-Whitney $U$ tests and Kruskal-Wallis tests were used for non-parametric data, and one-way ANOVA analyses were conducted on parametric data. Data on total I intake and the contribution of food groups to I intake were not normally distributed after transformation. Subsequently, the non-parametric Kruskal-Wallis and 
$\chi^{2}$ tests were used to study the relationships between demographic characteristics and total I knowledge on I intakes. To investigate whether I supplementation affected I knowledge, $\chi^{2}$ and one-way ANOVA analyses were conducted. Spearman's correlation analysis was used to assess the relationship between total dietary I intake and scores of I knowledge. Results for nonparametric data are presented as median values and interquartile ranges. Results for parametric data are presented as mean values and standard deviations. A $P$-value of $<0.05$ was considered statistically significant throughout.

\section{Results}

Table 1 outlines the participants' demographic characteristics. A total of 520 females completed the questionnaire, of whom $9 \%$ were smokers, $4 \%$ were currently pregnant and $2 \%$ were currently breast-feeding. A total of $5 \%$ reported diagnosis of a medical condition affecting the thyroid gland.

\section{lodine knowledge}

The mean total I knowledge score was $2 \cdot 1$ (SD 0.8 ) out of a maximum score of 8 (Table 1 ). The majority of participants had a mean I knowledge score between 1 and 3 (56\%). Table 1 outlines total I knowledge scores according to demographic characteristics. Those who previously received I information (9\%) had a significantly greater awareness of I, I deficiency and better knowledge of the dietary sources of I and the health problems associated with I deficiency than those who had never received information related to I (all $P<0.05$ ). Many of the current study participants who had obtained I nutrition information did so during time spent in formal education (75\%). Among other demographic characteristics, only age was associated with significant differences in total I knowledge scores (Table 1).

In general, participant awareness of I was low; only $43 \%$ of the participants were aware of the nutrient I. Those with a higher level of education had a significantly greater awareness of the nutrient I $(P=0.020)$ (data not shown). Knowledge of pregnancy as being the most important stage of the lifecycle for I was also low (Table 2). Age and employment status significantly affected participant knowledge, in that younger participants and those who were in either full or part-time employment or were currently studying were more likely to correctly identify pregnancy as the most important stage of the lifecycle for I nutrition in comparison with older participants $(P<0.001)$ and those who were unemployed, self-employed or retired $(P=0.008)$ (data not shown).

Almost half ( $41 \%$ ) of the participants 'did not know' or could not correctly identify any health problem associated with I deficiency. Goitre was recognised as a health problem associated with I deficiency in one-fifth of participant responses (19\%). Knowledge on the health problems resulting from I deficiency was lowest in Northern Ireland ( $n$ 355) in comparison with those from the Republic of Ireland ( $n$ 116) and other UK regions ( $n$ 49) $(P=0 \cdot 016)$ (data not shown). Knowledge of the health problems associated with I deficiency
Table 1. Participant characteristics ( $n$ 520) and the relationship between participant characteristics and total iodine knowledge scores $(0=$ poor knowledge, 8 = excellent knowledge) (Mean values and standard deviations)

\begin{tabular}{|c|c|c|c|c|c|}
\hline \multirow[b]{2}{*}{ Demographic data } & \multirow[b]{2}{*}{$n$} & \multirow[b]{2}{*}{$\%$} & \multicolumn{3}{|c|}{ Total I knowledge score } \\
\hline & & & Mean & SD & $P^{*}$ \\
\hline Total population & 520 & 100 & $2 \cdot 1$ & 0.8 & \\
\hline \multicolumn{6}{|l|}{ Age (years) } \\
\hline $18-25$ & 281 & $54 \cdot 0$ & $2 \cdot 3^{a}$ & $1 \cdot 8$ & 0.034 \\
\hline 26-30 & 75 & 14.4 & $1.9^{\mathrm{a}, \mathrm{b}}$ & 1.7 & \\
\hline $31-35$ & 61 & 11.7 & $2 \cdot 0^{\mathrm{a}, \mathrm{b}}$ & $1 \cdot 8$ & \\
\hline $36-40$ & 50 & $9 \cdot 6$ & $1 \cdot 8^{\mathrm{a}, \mathrm{b}}$ & 1.9 & \\
\hline $41-45$ & 53 & $10 \cdot 2$ & $1.6^{\mathrm{b}}$ & 1.5 & \\
\hline \multicolumn{6}{|l|}{ Ethnicity } \\
\hline Caucasian: British or Irish & 484 & $93 \cdot 1$ & $2 \cdot 0$ & $1 \cdot 7$ & 0.267 \\
\hline Caucasian: other & 21 & $4 \cdot 0$ & $2 \cdot 2$ & $1 \cdot 8$ & \\
\hline Asian: Chinese & 7 & $1 \cdot 3$ & 2.9 & $1 \cdot 6$ & \\
\hline Asian: other & 3 & 0.6 & $3 \cdot 3$ & 1.5 & \\
\hline Others & 5 & 1.0 & $3 \cdot 2$ & 0.8 & \\
\hline \multicolumn{6}{|l|}{ Home country } \\
\hline Northern Ireland & 355 & $68 \cdot 3$ & $2 \cdot 0$ & $1 \cdot 7$ & 0.065 \\
\hline Republic of Ireland & 116 & $22 \cdot 3$ & 2.4 & $1 \cdot 7$ & \\
\hline Scotland & 4 & 0.8 & 2.5 & $1 \cdot 7$ & \\
\hline Wales & 1 & 0.2 & 0.0 & 0.0 & \\
\hline England & 16 & $3 \cdot 1$ & 1.9 & $1 \cdot 6$ & \\
\hline Others & 28 & $5 \cdot 4$ & $2 \cdot 6$ & $1 \cdot 7$ & \\
\hline \multicolumn{6}{|l|}{ Education - highest level attained } \\
\hline Secondary: GCSE or equivalent & 7 & 1.3 & 1.4 & $1 \cdot 3$ & 0.337 \\
\hline $\begin{array}{l}\text { Secondary: A-Level or } \\
\text { equivalent }\end{array}$ & 162 & $31 \cdot 2$ & $2 \cdot 2$ & $1 \cdot 7$ & \\
\hline Further: BTEC or equivalent & 62 & 11.9 & 1.9 & $1 \cdot 7$ & \\
\hline $\begin{array}{l}\text { Higher: undergraduate } \\
\text { degree (BSc) }\end{array}$ & 172 & $33 \cdot 1$ & $2 \cdot 0$ & $1 \cdot 7$ & \\
\hline $\begin{array}{l}\text { Higher: postgraduate degree } \\
\text { (MSc or PhD) }\end{array}$ & 117 & $22 \cdot 5$ & $2 \cdot 2$ & $1 \cdot 8$ & \\
\hline \multicolumn{6}{|l|}{ Employment status } \\
\hline Work part-time & 91 & $17 \cdot 5$ & 1.9 & 1.9 & 0.267 \\
\hline Work full-time & 153 & $29 \cdot 4$ & 1.9 & 1.6 & \\
\hline Unemployed & 8 & 1.5 & $1 \cdot 6$ & $1 \cdot 8$ & \\
\hline Student & 247 & 47.5 & $2 \cdot 3$ & $1 \cdot 7$ & \\
\hline Self-employed & 5 & 1.0 & $1 \cdot 6$ & 0.9 & \\
\hline Retired & 1 & 0.2 & 3.0 & 0.0 & \\
\hline Others & 15 & 2.9 & 1.9 & $2 \cdot 0$ & \\
\hline \multicolumn{6}{|l|}{ Pregnancy } \\
\hline Currently pregnant & 19 & $3 \cdot 7$ & $2 \cdot 3$ & $1 \cdot 7$ & 0.813 \\
\hline Not pregnant & 496 & 95.4 & $2 \cdot 1$ & $1 \cdot 7$ & \\
\hline Unsure & 5 & 1.0 & 2.4 & 1.9 & \\
\hline \multicolumn{6}{|l|}{ Breast-feeding } \\
\hline Currently breast-feeding & 8 & 1.5 & $2 \cdot 1$ & 1.6 & 0.965 \\
\hline Not breast-feeding & 512 & 98.5 & $2 \cdot 1$ & $1 \cdot 7$ & \\
\hline \multicolumn{6}{|l|}{ Smoking status } \\
\hline Currently smokes & 46 & $8 \cdot 8$ & $1 \cdot 8$ & 1.5 & 0.165 \\
\hline Not smoking & 474 & $91 \cdot 2$ & $2 \cdot 1$ & $1 \cdot 8$ & \\
\hline \multicolumn{6}{|l|}{ Thyroid condition } \\
\hline $\begin{array}{l}\text { Has a previously diagnosed } \\
\text { thyroid condition }\end{array}$ & 25 & $4 \cdot 8$ & $2 \cdot 2$ & 1.9 & 0.534 \\
\hline $\begin{array}{l}\text { No previously diagnosed } \\
\text { thyroid condition }\end{array}$ & 481 & 92.5 & $2 \cdot 1$ & $1 \cdot 7$ & \\
\hline Unsure & 14 & $2 \cdot 7$ & $2 \cdot 6$ & $1 \cdot 8$ & \\
\hline \multicolumn{6}{|l|}{ I information } \\
\hline $\begin{array}{l}\text { Previously received } \\
\text { I information }\end{array}$ & 47 & $9 \cdot 0$ & $3.9^{a}$ & $1 \cdot 8$ & $<0.001$ \\
\hline $\begin{array}{l}\text { Never received } \\
\text { I information }\end{array}$ & 456 & $87 \cdot 7$ & $1.9^{b}$ & 1.6 & \\
\hline Unsure & 17 & $3 \cdot 3$ & $1.9^{b}$ & 1.5 & \\
\hline
\end{tabular}

GCSE, General Certificate of Secondary Education; A-Level, Advanced Level; BTEC, Business and Technology Education Council.

a,b Mean values within a column with unlike superscript letters were significantly different $(P<0.05)$.

* $P$ value for comparison between groups from independent $t$ test, Mann-Whitney $U$ test, ANOVA or Kruskal-Wallis test. 
Table 2. Knowledge of the stage of lifecycle when iodine is most important as identified by participants

(Numbers and percentages)

\begin{tabular}{lcr}
\hline Population groups & $n$ & \multicolumn{1}{c}{$\%$} \\
\hline Pregnant and breast-feeding women & 161 & 31.0 \\
Babies and young children & 103 & 19.8 \\
Teenagers & 41 & 7.9 \\
Adults & 41 & 7.9 \\
Elderly adults & 10 & 1.9 \\
Do not know & 164 & 31.5 \\
\hline
\end{tabular}

$n$, Number of participants; $\%$, percentage of participants.

* Denotes correct answer.

Table 3. Participant identification of the food groups richest in iodine in the UK and Ireland

(Numbers and percentages)

\begin{tabular}{lrr}
\hline & $n$ & $\%$ \\
\hline Nuts and seeds & 24 & $4 \cdot 6$ \\
Breakfast cereals $^{\prime}$ & 11 & $2 \cdot 1$ \\
Fish and seafood $^{*}$ & 201 & $38 \cdot 7$ \\
Milk and dairy products* & 45 & $8 \cdot 7$ \\
Eggs & 15 & $2 \cdot 9$ \\
Meat and meat products & 42 & $8 \cdot 1$ \\
Bread & 4 & $0 \cdot 8$ \\
Vegetables & 38 & $7 \cdot 3$ \\
Salt & 27 & $5 \cdot 2$ \\
Fruits & 5 & $1 \cdot 0$ \\
Do not know & 108 & $20 \cdot 8$ \\
\hline
\end{tabular}

$n$, Number of participants; \%, percentage of participants.

* Denotes correct answers.

was not significantly related to any other demographic characteristic.

As shown in Table 3, 39\% of the participants identified fish and seafood as the richest source of I and only 9\% identified milk and dairy products. Younger participants (18-25 years) had significantly better knowledge of the dietary sources of I than older participants $(41-45$ years) $(P<0.001)$ (data not shown). Knowledge of the dietary sources of I was not significantly different among women who were pregnant or breast-feeding. Less than one-third (27\%) of participants were aware that I deficiency is a current public health concern in the UK and Ireland. Those who had been diagnosed with a thyroid condition ( $n$ 25) had a significantly greater awareness of I deficiency as a current health problem in the UK and Ireland than those who did not have a thyroid condition ( $n$ 481) $(P<0.001)$ (data not shown)

\section{Dietary iodine intake}

Complete dietary I intake data were available for 502 participants. The median daily I intake was estimated as 152 (interquartile range $98-213) \mu \mathrm{g} / \mathrm{d}$. A total of $46 \%$ of the participants failed to meet the RNI of $140 \mu \mathrm{g}$ of I/d (Fig. 1). I intake was not significantly different between age groups $(P=0.080)$ (data not shown). A significantly greater percentage of unemployed and self-employed participants failed to meet the RNI compared with those who were in full-time or part-time employment or studying ( $83 v .45 \% ; P=0.008$ ) (data not shown). There was no association between total daily I intake, being currently pregnant or breast-feeding, level of education, smoking status, diagnosis of a thyroid condition or having previously received I information (all $P>0.05$ ) (data not shown).

Milk and dairy products made the largest contribution to I intake in this cohort as detailed in Table 4 . Older participants (31-45 years) had a significantly higher I intake from milk than younger participants $(18-31$ years) $(P=0.025)$ (data not shown). The majority of participants never consumed organic milk (74\%), 20\% consumed organic milk sometimes and 6\% consumed organic milk often or always. Iodised salt was not widely consumed; only $7 \%$ stated that they purchased iodised salt for use at home. Participants who stated that they consumed iodised salt ( $n$ 37) were asked to state which iodised salt brand they consumed, and in total twelve salt brands were listed. Contact was made with the salt manufacturers, and none of the salts listed by participants were found to have been fortified with I. One manufacturer reported that their salt contained trace amounts of I, and this means that I was present in the salt but not at a level that can be accurately measured. Only $4 \%$ of the women surveyed reported consuming a supplement containing I. Although supplement consumption was significantly greater in pregnant or breast-feeding women than non-pregnant and non-breastfeeding women $(P=0 \cdot 010)$, only $12 \%$ of pregnant or breast-feeding women reported consuming an I-containing supplement (data not shown). On the basis of manufacturers' label information, ten of the thirteen dietary supplements consumed by participants contained I. The I content of these supplements ranged from 100 to $200 \mu \mathrm{g}$ per recommended daily dosage, and the average I content was $132 \mu \mathrm{g}$ per recommended daily dosage.

\section{Relationship between iodine knowledge and iodine intake}

There was a weak positive association between total daily I intake and total I knowledge score as outlined in Table 5. Of those participants with a daily I intake above the LRNI, significantly more participants were aware of the nutrient I compared with those with an intake below the LRNI $(P=0.043)$ (data not shown). A higher daily I intake from fish and dairy products was positively associated with awareness of I and knowledge of the health problems associated with I deficiency $(P<0 \cdot 050)$ (data not shown). Women consuming supplements ( $n$ 18) containing I had a significantly better awareness of the nutrient I, knowledge of I and of the health problems associated with I deficiency compared with those not consuming a supplement $(P<0 \cdot 020)$ (data not shown).

Those who reported consuming organic milk 'often' ( $n$ 21) or 'always' ( $n$ 9) had a significantly lower awareness of the nutrient I than those who 'sometimes' or 'never' consumed organic milk ( $P=0.039)$ (data not shown). Consumption of organic milk was negatively associated with total I knowledge; significantly more women who reported consuming organic milk 'often' or 'always' had a total I knowledge score of 0 $(P=0 \cdot 008)$ (data not shown). 


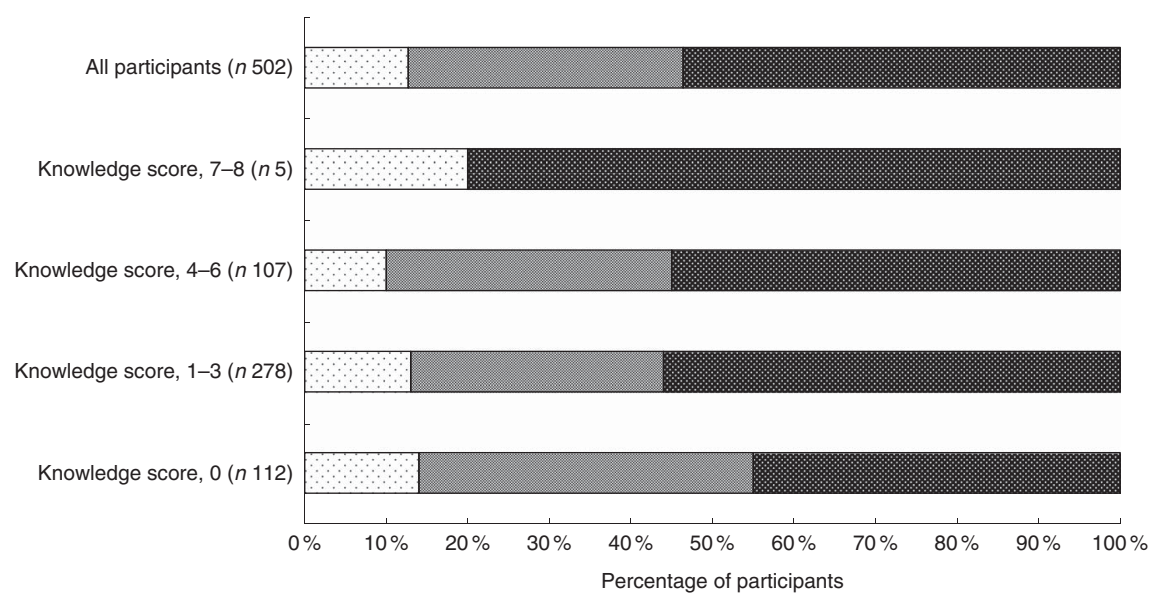

Fig. 1. Percentage of respondents with daily iodine intake below the lower reference nutrient intake (LRNI) $(\leq 70 \mu \mathrm{g} / \mathrm{d})$, between the LRNI and the reference nutrient intake (RNI) $(70 \cdot 1-139.9 \mu \mathrm{g} / \mathrm{d})$ and meeting the RNI $(\geq 140 \mu \mathrm{g} / \mathrm{d})^{(10)}$. $\square,<\mathrm{LRNI} ; \square, \mathrm{LRNI}-\mathrm{RNI}$; , >RNI.

Table 4. The contribution of food groups to total daily iodine intake in women of childbearing age

(Medians and 25th-75th percentiles)

\begin{tabular}{lccc}
\hline Food groups & $\begin{array}{c}\text { Contribution } \\
\text { to total } \\
\text { I intake }(\%)\end{array}$ & $\begin{array}{c}\text { Median I } \\
\text { contribution } \\
(\mu \mathrm{g})\end{array}$ & $\begin{array}{c}\text { 25th-75th } \\
\text { percentiles } \\
(\mu \mathrm{g})\end{array}$ \\
\hline Milk & 46.1 & 60.0 & $34.3-94 \cdot 3$ \\
$\begin{array}{l}\text { Other dairy products } \\
\quad \text { cheese, yogurts, milk }\end{array}$ & 24.2 & 31.5 & $12.5-61.7$ \\
$\quad$ based puddings) & & & \\
$\begin{array}{l}\text { Fish and seafood } \\
\text { Egg and egg dishes }\end{array}$ & 19.2 & 25.0 & $12.9-56.2$ \\
\hline
\end{tabular}

Table 5. Associations between daily iodine intake and iodine knowledge and awareness

\begin{tabular}{|c|c|c|}
\hline I knowledge and awareness parameters & $\begin{array}{l}\text { Correlation } \\
\text { coefficient }\end{array}$ & $P$ \\
\hline $\begin{array}{l}\text { Knowledge of the stage of lifecycle I when is } \\
\text { most important* }\end{array}$ & & 0.700 \\
\hline Knowledge of the dietary source of $\mathrm{I}^{*}$ & & 0.472 \\
\hline Awareness of the nutrient $I^{*}$ & & 0.754 \\
\hline $\begin{array}{l}\text { Awareness of I deficiency as a public health } \\
\text { concern* }\end{array}$ & & 0.642 \\
\hline $\begin{array}{l}\text { Knowledge of the health problems associated } \\
\text { with I deficiency } \dagger\end{array}$ & 0.097 & 0.030 \\
\hline Total I knowledge† & 0.107 & 0.016 \\
\hline
\end{tabular}

* Assessed by Kruskal-Wallis test.

† Assessed by Spearman's correlation analysis.

\section{Discussion}

Despite growing concern regarding the prevalence of I deficiency among women of childbearing age in the UK and Ireland, the present study has shown that there is a lack of I knowledge among this population group. Women of childbearing age were shown to have limited knowledge of the dietary sources of I, the problems arising from deficiency and the population group most at risk of deficiency. The present findings also indicate that women of childbearing age are relatively unaware of I deficiency as a current health problem in the UK and Ireland. Similar levels of I knowledge have been reported in previous studies in other countries, and it has been suggested that a low level of knowledge surrounding $\mathrm{I}$ is a major factor contributing to the risk of I deficiency ${ }^{(17-22)}$. As demonstrated by the present study, I knowledge was positively associated with I intake. Therefore, a poor knowledge of dietary I sources helps explain why almost half of the participants had a daily I intake below the RNI. Similar to the latest National Diet and Nutrition Survey findings, $13 \%$ of the participants in the current study failed to meet the LRNI ${ }^{(12)}$. Factors such as socioeconomic status and food availability may also in part explain why dietary recommendations were not met. These findings also suggest that it may be difficult for women who become pregnant to ensure an adequate daily I intake, given that their knowledge of the dietary I sources is poor.

There have been several measures implemented worldwide to eradicate I deficiency with the primary method being salt iodisation. Policy makers in the UK and Ireland have been reluctant to implement an iodised salt policy, and therefore viable alternatives to iodised salt are important for increasing I status and preventing deficiency. The current study confirms that iodised salt is not widely consumed, and is therefore unlikely to contribute significantly to I intake, consistent with previous studies ${ }^{(16,29)}$. I-containing supplements were not widely consumed by this cohort, and there was large variability in the I content of nutritional supplements. The results of this survey also indicate that there is a lack of awareness about which nutritional supplements and salt brands contain I. It is noteworthy that approximately one-fifth of the participants were consumers of organic milk, although only 'sometimes', as recent research has found that organic milk typically contains $30 \%$ less I than conventional milk ${ }^{(15,30)}$. Organic milk consumers in the present study had a significantly lower I intake than conventional milk consumers. In general, women of childbearing age should be made more aware of the dietary sources of I. Those who avoid milk and dairy products may be at risk of consuming insufficient I as conventional cow's milk makes the largest contribution to dietary I intakes in many 
countries including the UK and Ireland ${ }^{(12,31)}$. Observational evidence from several countries has consistently reported milk consumption to be positively associated with I intake and status $^{(32-34)}$. It should also be communicated to pregnant women and women of childbearing age that organic milk has a lower I concentration and they should be made aware of other dietary I sources.

There is a clear need for greater public awareness of the importance of I nutrition for health. Previous studies have investigated how women of childbearing age would prefer to have I nutrition education, and reported that information delivered via health practitioners or mass media was the preferred option ${ }^{(19)}$. Mass media strategies are integral to increasing public awareness and knowledge and should be considered for increasing I knowledge ${ }^{(35)}$. There is also a need to update healthcare professionals, particularly those involved in the care of women planning a pregnancy, on the importance of I as previous research has demonstrated that midwives and other healthcare professionals have a low level of I knowledge $^{(36-38)}$. To address I deficiency sufficiently, healthcare professionals will be instrumental as they are in a position to advocate for policy change both within their own practices and in the external policy environment. I knowledge was still relatively low for those who had previously received I information, and it could therefore be recommended that changes to the curriculum and informing educators on the importance of I nutrition may be beneficial for improving knowledge and awareness of I. To target teenage girls and younger women before pregnancy may be the most valuable public health strategy given that maternal I stores are essentially utilised during the first trimester ${ }^{(8)}$.

There are a number of considerations to be taken into account when interpreting the present study's findings. When compared with UK population data for females, there was a lower smoking prevalence and a higher prevalence of thyroid disorders in this cohort of women of childbearing age ${ }^{(39,40)}$. Furthermore, this was largely a Northern Irish population (68\%), and compared with national averages for the UK a higher proportion of the women who participated in this study had a university degree owing to recruitment primarily within a university setting. Considering that this cohort had attained higher levels of education it is likely that I knowledge in the general population may be lower ${ }^{(41,42)}$. There were some differences in I knowledge and awareness according to employment status and highest level of education attained, which may be indicative of socio-economic status. Future studies should investigate the potential barriers to I knowledge and status in women of childbearing age with lower socio-economic status. This research could potentially be used to inform policy in the context of increasing I knowledge, dietary intake, and thus status.

This study was limited at assessing the I knowledge of pregnant and breast-feeding women as there were a few pregnant and breast-feeding participants. However, given their low level of knowledge previously reported ${ }^{(22,24,37,43)}$, educational intervention among pregnant and breast-feeding women should be considered. A number of these studies were conducted in Australia and New Zealand, and these studies ${ }^{(24,37,43)}$ were conducted at a time when mandatory bread fortification with iodised salt had been introduced; however, I knowledge was low. Australia and New Zealand are also industrialised countries at a similar stage of economic development as the UK and are countries that share similar political and legal systems, diets and cultures as the UK, which increases the comparability of studies between countries.

Estimating dietary I intake presents many challenges, and when using FFQ to estimate dietary intake there are inherent limitations such as precision and reporting bias to be taken into account ${ }^{(44,45)}$. It is also recognised that FFQ often overestimate the intake of 'healthy' foods and underestimate the intake of more 'unhealthy' foods ${ }^{(46)}$. In the context of this study, estimated I intakes from the FFQ may be overestimated and I intakes may be lower than reported. The FFQ used as part of this study has previously been validated in women of childbearing age ${ }^{(27)}$ and was the best available FFQ for assessing I intake. The large sample size in the present study may increase the validity of I intake estimations from the FFQ. The FFQ used was I specific and was validated for estimating I intake at a group level, making it suitable for the current study. However, it was not designed to estimate I intake at the individual level and, as such, there is a possibility that some participants may have been misclassified $(<\mathrm{RNI})$ on the basis of their I intake. A further limitation of this study is that dietary I intake was only captured on one occasion. There is also concern regarding the over-interpretation of distribution data both for urinary iodine concentration (UIC) and dietary intakes. A new approach has been suggested whereby UIC are extrapolated to dietary I intake, which is then adjusted for intraindividual variation and interpreted according to estimated average requirement ${ }^{(47)}$. To corroborate the findings reported here, biomarkers of I intake should be measured including UIC and thyroglobulin, a promising biomarker of I status ${ }^{(48)}$, to further investigate the association between I knowledge and I intake in women of childbearing age.

\section{Conclusion}

This study is the first to investigate I nutrition knowledge among women of childbearing age in the UK and Ireland. A low level of I knowledge was apparent and this was reflected in the low dietary I intake and the infrequency of consumption of I-containing supplements. As part of a larger public health policy to eradicate I deficiency, educational intervention should be considered. Among women of childbearing age, targeted public health campaigns are warranted to increase I nutrition knowledge and intake.

\section{Acknowledgements}

The authors wish to thank all the study participants.

S. M. O. is in receipt of a postgraduate studentship from the Department of Agriculture, Environment and Rural Affairs (DAERA), which funded this research. DAERA had no role in the design, analysis or writing of this article.

A. J. Y., L. K. P., M. S. M. and J. J. S. were responsible for the study design. K. M. F., L. K. P., A. J. Y. and S. M. O. designed 
the questionnaire and obtained ethical approval. S. M. O. and K. M. F. were responsible for data collection. S. M. O. conducted statistical analysis with guidance from L. K. P. S. M. O. prepared the initial manuscript, which was edited by L. K. P., A. J. Y., M. S. M. and J. J. S. All authors read and approved the final version of the manuscript.

The authors declare that there are no conflicts of interest.

\section{Supplementary material}

For supplementary material/s referred to in this article, please visit https://doi.org/10.1017/S0007114516003925

\section{References}

1. Halpern JP, Boyages SC, Maberly GF, et al. (1991) The neurology of endemic cretinism, a study of two endemias. Brain 114, 825-841.

2. Kapil U (2007) Health consequences of iodine deficiency. Sultan Qaboos Univ Med J 7, 267-272.

3. Zimmermann MB (2009) Iodine deficiency. Endocr Rev 30, 376-408

4. Bath SC, Steer CD, Golding J, et al. (2013) Effect of inadequate iodine status in UK pregnant women on cognitive outcomes in their children: results from the Avon Longitudinal Study of Parents and Children (ALSPAC). Lancet 382, 331-337.

5. Nawoor Z, Burns R, Smith DF, et al. (2006) Iodine intake in pregnancy in Ireland - a cause for concern? Ir J Med Sci 175 $21-24$.

6. Rayman M, Sleeth M, Walter A, et al. (2008) Iodine deficiency in UK women of child-bearing age. Proc Nutr Soc 67, E399.

7. Lampropoulou M, Lean MEJ \& Combet E (2012) Iodine status of women of childbearing age in Scotland. Proc Nutr Soc 71, E143.

8. Glinoer D (1997) The regulation of thyroid function in pregnancy: pathways of endocrine adaption from physiology to pathology. Endocr Rev 18, 404-433.

9. Bath SC \& Rayman MP (2015) A review of the iodine status of UK pregnant women and its implications for the offspring. Environ Geochem Health 37, 619-629.

10. Committee on Medical Aspects of Food Policy (1991) Dietary Reference Values for Food Energy and Nutrients for the United Kingdom. Department of Health, Report on Health and Social Subjects, no. 41. London: The Stationery Office.

11. World Health Organization, United Nations International Children's Emergency Fund \& International Council for Control of Iodine Deficiency Disorders (2007) Assessment of iodine deficiency disorders and monitoring their elimination. http://whqlibdoc.who.int/publications/2007/9789241595827_ eng.pdf (accessed March 2016).

12. Bates B, Lennox A, Prentice A, et al. (2014) National Diet and Nutrition Survey. Results from years 1, 2, 3, and 4 (combined) of the rolling programme (2008/2009-2011/2012). https:// www.gov.uk/government/uploads/system/uploads/attachment_ data/file/310995/NDNS_Y1_to_4_UK_report.pdf (accessed March 2016).

13. European Commission, Agricultural and Rural Development (1997) Appendix 2: EU milk consumption patterns, UK, France and Germany. http://ec.europa.eu/agriculture/eval/ reports/schoolmilk/appendix2.pdf (accessed April 2016).

14. Bath SC, Sleeth ML, McKenna M, et al. (2014) Iodine intake and status of UK women of childbearing age recruited at the University of Surrey in the winter. Br I Nutr $\mathbf{1 1 2}$, $1715-1723$

15. Bath SC, Button S \& Rayman MP (2012) Iodine concentration of organic and conventional milk: implications for iodine intake. Br J Nutr 107, 935-940.

16. Bath SC, Button S \& Rayman MP (2013) Availabilty of iodised table salt in the UK - is it likely to influence population iodine intake? Public Health Nutr 17, 450-454.

17. Jooste PL, Upson N \& Charlton KE (2005) Knowledge of iodine nutrition in the South African adult population. Public Health Nutr 8, 382-386.

18. Abuye C \& Berhane Y (2007) The goitre rate, its association with reproductive failure, and the knowledge of iodine deficiency disorders (IDD) among women in Ethiopia: cross-section community based study. BMC Public Health 7, 316-323.

19. Charlton KE, Yeatman HR \& Houweling F (2010) Poor iodine status and knowledge related to iodine on the eve of mandatory iodine fortification in Australia. Asia Pac J Clin Nutr 19, 250-255.

20. Charlton KE, Gemming L, Yeatman H, et al. (2010) Suboptimal iodine status of Australian pregnant reflects poor knowledge and practices related to iodine nutrition. Nutrition $\mathbf{2 6}$, 963-968.

21. Kim BK, Jeong JY, Seok KH, et al. (2014) Current iodine nutrition status and awareness of iodine deficiency in Tuguegarao, Philippines. Int J Endocrinol 2014, 210528.

22. Combet E, Bouga M, Pan B, et al. (2015) Iodine and pregnancy - a UK cross-sectional survey of dietary intake, knowledge and awareness. Br J Nutr 114, 108-117.

23. El-Mani S, Charlton KE, Flood VM, et al. (2014) Limited knowledge about folic acid and iodine in pregnant women reflected in supplementation practices. Nutr Diet $\mathbf{7 1}$, 236-244.

24. Martin JC, Savage GS \& Mitchell EKL (2013) Health knowledge and iodine intake in pregnancy. Aust $N Z J$ Obstet Gynaecol 54, 312-316.

25. Bath SC \& Rayman MP (2013) British Dietetic Association food fact sheet - iodine. https://www.bda.uk.com/foodfacts/Iodine (accessed March 2016).

26. Charlton K, Yeatman H, Lucas C, et al. (2012) Poor knowledge and practices related to iodine nutrition during pregnancy and lactation in Australian women: pre- and post-iodine fortification. Nutrients 4, 1317-1327.

27. Combet E \& Lean ME (2014) Validation of a short food frequency questionnaire specific for iodine in U.K. females of childbearing age. J Hum Nutr Diet 27, 599-605.

28. Food Standards Agency (2002) McCance and Widdowson's: The Composition of Foods, 6th summary edition. Cambridge, MA: Royal Society of Chemistry.

29. Bath SC, Steer CD, Emmett PM, et al. (2013c) Dietary factors that influence maternal iodine status in UK pregnant women. Proc Nutr Soc 72, E292.

30. Payling LM, Juniper DT, Drake C, et al. (2015) Effect of milk type and processing on iodine concentration of organic and conventional winter milk at retail: implications for nutrition. Food Chem 178, 327-330.

31. Food Safety Authority of Ireland (FSAI) (2011) Report on a total diet study carried out by the Food Safety Authority of Ireland in the period 2001-2005. https://www.fsai.ie/news_ centre/press_releases/total_diet_study_15032016.html (accessed June 2016).

32. Perrine CG, Herrick K, Serdula MK, et al. (2010) Some subgroups of reproductive age women in the United States may be at risk for iodine deficiency. J Nutr 140, 1489-1494.

33. Vanderpump MPJ, Lazarus JH, Smyth PP, et al. (2011) Iodine status of UK schoolgirls: a cross-sectional survey. Lancet $\mathbf{3 7 7}$, 2007-2012. 
34. Fernando SW, Cavedon E, Nacamulli D, et al. (2015) Iodine status from childhood to adulthood in females living in NorthEast Italy: iodine deficiency is still an issue. Eur J Nutr 55, 335-340.

35. Mehran L, Nazeri P, Delshad H, et al. (2012) Does a text messaging intervention improve knowledge, attitudes and practice regarding iodine deficiency and iodized salt consumption? Public Health Nutr 15, 2320-2325.

36. Williamson C, Lean MEJ \& Combet E (2012) Dietary iodine: awareness, knowledge and current practice among midwives. Proc Nutr Soc 71, E142.

37. Lucas CJ, Charlton KE, Brown E, et al. (2014) Antenatal shared care: are pregnant women being adequately informed about iodine and nutritional supplementation? Aust $N Z$ J Obstet Gynaecol 54, 515-521.

38. El-Mani SF, Mullan J, Charlton KE, et al. (2014) Folic acid and iodine supplementation during pregnancy: how much do pharmacists know and which products are readily available? J Pharm Pract Res 44, 113-119.

39. Vanderpump MP, Tunbridge WM \& French JM (1995) The incidence of thyroid disorders in the community: a twenty-year follow-up of the Whickham Survey. Clin Endocrinol 43, 55-68.

40. Public Health Agency (2015) Tobacco Control Northern Ireland. Belfast: PHA.
41. Northern Ireland Statistics and Research Agency (2012) Census 2011: key statistics for Northern Ireland. http://www.nisra.gov. uk/Census/key_stats_bulletin_2011.pdf (accessed March 2016).

42. Office for National Statistics (2014) Local area analysis of qualifications across England and Wales. http://www.ons.gov. uk/ons/dcp171776_355401.pdf (accessed March 2016).

43. Axford S, Charlton K, Yeatman H, et al. (2012) Poor knowledge and dietary practices related to iodine in breastfeeding mothers a year after introduction of mandatory fortification. Nutr Diet 69, 91-94.

44. Byers T (2001) Food frequency dietary assessment: how bad is good enough? Am J Epidemiol 154, 1087-1088.

45. Kristal AR, Peters U \& Potter JD (2005) Is it time to abandon the food frequency questionnaire? Cancer Epidemiol Biomarkers Prev 14, 2826-2828.

46. Fallaize R, Forster H, Macready AL, et al. (2014) Online dietary intake estimation: reproducibility and validity of the Food4Me food frequency questionnaire against a 4-day weighed food record. I Med Internet Res 16, e190.

47. Zimmermann MB \& Andersson M (2012) Assessment of iodine nutrition in populations: past, present, and future. Nutr Rev 70, 553-570.

48. Vejberg P, Knudsen N, Perrild H, et al. (2009) Thyroglobulin as a marker of iodine nutrition status in the general population. Eur J Endocrinol 161, 475-481. 